\title{
Effects of SEMA3G on migration and invasion of glioma cells
}

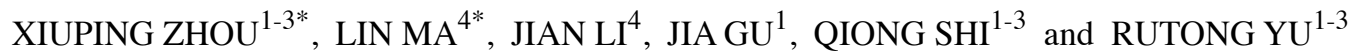 \\ ${ }^{1}$ Department of Neurosurgery and ${ }^{2}$ Key Laboratory of Brain Disease Biology, Affiliated Hospital of Xuzhou Medical College; \\ ${ }^{3}$ Laboratory of Neurosurgery and ${ }^{4}$ The Graduate School, Xuzhou Medical College, Xuzhou, Jiangsu, P.R. China
}

Received January 19, 2012; Accepted April 6, 2012

DOI: $10.3892 /$ or.2012.1796

\begin{abstract}
Glioblastoma multiforme is the most aggressive type of brain tumor with a strong ability to invade and migrate into surrounding normal brain tissues, leading to high tumor recurrence and mortality. Most of class-3 semaphorins, especially SEMA3A, SEMA3B and SEMA3F, have been reported to have strong tumor inhibition ability, but the role of SEMA3G in tumor biology is largely unknown. We report here that SEMA3G possesses anti-migration and anti-invasion ability. To determine the potential effects of SEMA3G on migratory and invasive ability, we generated stable SEMA3G expression U251MG cells. We found that stably overexpressed SEMA3G inhibited the migratory and invasive behavior of U251MG cells. In addition, treatment with SEMA3G conditioned media also decreased the migratory and invasive ability of parental U251MG cells. Furthermore, SEMA3G also inhibited the activity of MMP2, an index of tumor invasion ability. Thus, our results suggest that SEMA3G inhibited tumor cell migration and invasion, which may be obtained through cell autonomous or paracrine mechanisms, and SEMA3G is a potential target for antitumor migration and invasion.
\end{abstract}

\section{Introduction}

Glioblastoma multiforme is the most common and aggressive type of brain tumor characterized by dissemination and infiltration of tumor cells into the brain stroma (1). As the infiltrating tumor cells are the source of tumor recurrence, the invasive nature of tumor cells makes a critical contribution to the ineffectiveness of current treatment modalities, suggesting the urgent need to understand in more detail the mechanisms of tumor invasiveness (2).

Class-3 semaphorins (SEMA3s) are a group of secreted glycoproteins of $\sim 100 \mathrm{kDa}$ consisting of seven subtypes (desig-

Correspondence to: Dr Rutong Yu, Department of Neurosurgery, Affiliated Hospital of Xuzhou Medical College, 99 West Huai-hai Road, Xuzhou, Jiangsu 221002, P.R. China

E-mail: yu.rutong@163.com

${ }^{*}$ Contributed equally

Key words: glioma, SEMA3G, migration, invasion, MMP2 nated by the letters A-G), which are initially implicated in the development of the nervous system and in axon guidance (3). More recently, SEMA3s have been found to act as pleiotropic signals that are able to control multiple functions in tumor cells, ranging from survival, proliferation and apoptosis to cell adhesion and migration (4-7). Of the SEMA3 family members, SEMA3A, SEMA3B, and SEMA3F have the best-described roles in tumor growth and metastasis. For example, SEMA3A can dramatically inhibit the proliferation of breast cancer cells both in soft agar in vitro and in tumor models in vivo (8). In addition, SEMA3A is also found to reduce both the migratory and invasive behavior of breast tumor cells $(9,10)$. The expression level of SEMA3B in tumor tissues is correlated with poor prognosis and metastatic progression $(11,12)$. Consistently, SEMA3B overexpression in tumor cell lines induces apoptosis $(13,14)$ and inhibits cell proliferation and colony formation in soft agar $(5,15,16)$. SEMA3F expression also inversely correlates with lung-cancer tumor grading and staging (17). In addition, overexpression of SEMA3F in tumor cells inhibits proliferation, prevents anchorage-independent growth (18-20) and potently inhibits tumorigenesis in vivo (16). Moreover, SEMA3F inhibits cell-spreading and migration in breast carcinoma (6), melanoma cells (21) and colorectal cancer cells (22). Taken together, these findings suggest that SEMA3A, SEMA3B, and SEMA3F inhibit tumor growth. Although most members of the SEMA3s have been shown to be inhibitory, some promote tumor growth and metastasis (23). For instance, SEMA 3C promotes glomerular endothelial cell proliferation, adhesion, directional migration, and tube formation in vitro (24). Therefore, the role and mechanism of SEMA3 family proteins in tumor biological behavior need more extensive and intensive study.

Among SEMA3 family proteins, there are few studies on SEMA3G, and its role and mechanism in tumor biology are largely unknown. Although it is reported that overexpression of SEMA3G can inhibit breast cancer and melanoma growth and angiogenesis $(8,25)$, its role in the inhibition of invasion and migration has not been reported. Because SEMA3s exert its function by interacting with its receptors neuropilins (NRP) and plexins (23) and SEMA3G receptor NRP2 participates in human glioma progression (26), we designed this study to determine the role of SEMA3G in glioma cell migration and invasion ability. In this study, we generated the SEMA3G stable expressing human glioblastoma U251 (U251MG) cell line and then examined the migratory and invasive behavior. We found that SEMA3G inhibited the migration and invasion abilities of U251 MG cells dramatically. The culture media from stable 
SEMA3G expression U251MG cell (SEMA3G conditioned media) treatment also inhibited the migration and invasion abilities of naïve U251MG cells. Thus, our results indicated that SEMA3G acted in a cell autonomous or a paracrine fashion to affect tumor cell migration and invasion.

\section{Materials and methods}

Stable SEMA $3 G$ overexpressing U251 MG cell generation. U251MG cells (purchased from Shanghai Cell Bank, Type Culture Collection Committee, Chinese Academy of Sciences) were maintained in DMEM supplemented with $10 \%$ fetal bovine serum and transfected with pEGFP-N1-SEMA3G or pEGFP-N1 respectively using Lipofectamine 2000 (Invitrogen) according to the manufacturer's instructions. The SEMA 3G-GFP construct was purchased from Shanghai Minghong Biotech, which was generated by cloning the human SEMA 3G cDNA into the expression vector pEGFP-N1 at the EcoRI and $K p n I$ restriction sites. After 24-h transfection, cells were maintained in DMEM containing G418 $(1000 \mu \mathrm{g} / \mathrm{ml})$ for $\sim 2$ weeks and the living GFP positive clones were picked up, digested with trypsin and living cells were counted via trypan blue staining. The isolated cells were plated into a 96-well plate with only one cell per well using limiting dilution and cultured with DMEM containing G418 $(500 \mu \mathrm{g} / \mathrm{ml})$ for maintaining selection pressure. About 2 weeks later, the big single cell clone was obtained, digested with trypsin and the isolated cells were plated into a 12-well plate. After the cells were grown to $90 \%$ confluence, they were transferred to a flask for more cells. The culture media and the cell lysates were collected and examined by RT-PCR or western blotting to analyze the expression and secretion of SEMA 3G-GFP. The media of positive cells were collected and the cells were frozed for future use. The cells were cultured under G418 selection pressure at all times.

Reverse transcription-polymerase chain reaction. Total RNA of U251MG cells was extracted using the TRIzol reagent (Tiangen Biotech Co.). First-strand cDNA was synthesized in a $20-\mu 1$ reaction volume using the reverse transcription reagents [Takara RNA PCR Kit (AMV) Ver.3.0] according to the manufacturer's instructions. Primers (Sangon Biotech Co.) for SEMA 3G were as follows: sense: 5'-GGG TCT GTG CTC AAA GTC ATC G-3'; antisense: 5'-AAG TCC CAC TGC CTC TTC TTC C-3'. Primers for GAPDH were: sense: 5'-AGA AGG CTG GGG CTC ATT TG-3'; antisense: 5'-AGG GGC CAT CCA CAG TCT TC-3' yielding a product as a reference. Polymerase chain reaction conditions were: the first-strand DNA template was heated at $94^{\circ} \mathrm{C}$ for $3 \mathrm{~min}$ before amplification, a total of 30 cycles were used including at $94^{\circ} \mathrm{C}$ for $30 \mathrm{sec}$ (denaturation), at $55^{\circ} \mathrm{C}$ for 30 sec (annealing) and at $72^{\circ} \mathrm{C}$ for $1 \mathrm{~min}$ (extension) and another $72^{\circ} \mathrm{C}$ for $5 \mathrm{~min}$ (extension).

Western blot analysis. Cells were lysed in western blot lysis buffer [50 mM Tris-HCl (pH 8.0), $150 \mathrm{mM} \mathrm{NaCl}, 1 \% \mathrm{NP}-40$, 2 mM EDTA (pH 8.0), $10 \mathrm{mMNaF}, 1 \mathrm{mM} \mathrm{Na}_{3} \mathrm{VO}_{4}, 1 \mathrm{mM}$ PMSF, aprotinin and leupeptin each at $10 \mathrm{pg} / \mathrm{ml}, 0.5 \%$ deoxycholic acid, and $0.1 \% \mathrm{SDS}$ ] for $30 \mathrm{~min}$ on ice. Protein lysates were concentrated using the BCA Protein Assay kit (Thermo Scientific) and equal amount of protein lysates or equal volume of media were subjected to $12 \%$ sodium dodecyl sulfate-polyacrylamide gel electrophoresis, then transferred to polyvinylidene difluoride membrane of $0.45-\mu \mathrm{m}$ pore size (Millipore), and probed with primary antibodies (GFP or $\beta$-actin) at $4^{\circ} \mathrm{C}$ overnight and horseradish peroxidase-conjugated secondary antibodies at room temperature for $2 \mathrm{~h}$. Bound antibodies were detected by the Pierce ECL Plus Western Blotting Substrate (Thermo Fisher Scientific Inc.) and exposed to X-ray film. Band densities were quantified by ImageJ software, and the densitometric results were shown. The relative amount of proteins was determined by normalizing the densitometry value of interest to that of the internal loading control. Western blot experiments were carried out in three biological replicates and average fold changes were reported.

Cell migration assay. The migration behavior of cells was evaluated using a wound healing assay. U251MG cells were grown to confluence in 6-well plates. Twenty-four hours after stable SEMA 3G expression cell plating or SEMA 3G conditioned media treatment, linear wounds were created by scraping confluent cell monolayer with a sterile blade in a definite array. The monolayer was rinsed twice with PBS and incubated in serum-free media or SEMA 3G conditioned media. At the initiation of the experiment $(0 \mathrm{~h})$, five randomly selected fields at the lesion border were acquired using a CCD camera on an inverted microscope (Olympus, IX71) and 24 or $48 \mathrm{~h}$ later the same region was imaged again. The total migratory cells into the wound area and the farthest distance migrated were quantified as the cell mobility ability index. Experiments were done at least three times and measurements were made in triplicate $(27,28)$.

Cell invasion assay. The transwell matrigel invasion assays were used to assess the effect of SEMA3G on the invasiveness of cancer cells. Briefly, cell invasion assays were performed using insert membranes $(8.0-\mu \mathrm{m}$ pore size with polycarbonate membrane; Corning Incorporated) precoated with diluted matrigel (BD Biosciences, San Jose, CA, USA) according to the manufacturer's instructions. A cell suspension $\left(1 \times 10^{5}\right)$ in serumfree culture media was added to the inserts, and each insert was placed in the lower chamber filled with culture media containing $10 \%$ FBS. To test the invasion ability of SEMA 3G conditioned media treated cells, after treated with SEMA 3G conditioned media for $24 \mathrm{~h}$, cell suspension in SEMA $3 \mathrm{G}$ conditioned media were plated onto the top of the inserts which was placed in the lower chamber filled with culture media containing $10 \%$ FBS. After 24-h incubation, the non-invading cells remaining on the upper surface of the membrane were removed by wiping with cotton-tipped swabs. Cells on the lower surface of the membrane were stained with crystal violet and 5 fields of adherent cells in each well were randomly photographed under an inverted microscope and counted. Experiments were repeated at least three times $(27,29)$.

Gelatin substrate gel zymography. Gelatin substrate gel zymography was performed to examine the gelatinase MMP2 activity which was an index of cell invasion ability. After 24-h incubation with serum-free DMEM, the conditioned media was collected and centrifuged for $5 \mathrm{~min}$ at $10,000 \mathrm{x} \mathrm{g}$ to discard unsoluble materials. Equal volume of conditioned media was mixed with SDS loading buffer in the absence of sulfhydryl reducing agent and electrophoresed in $10 \%$ SDS polyacrylamide gel containing 
A

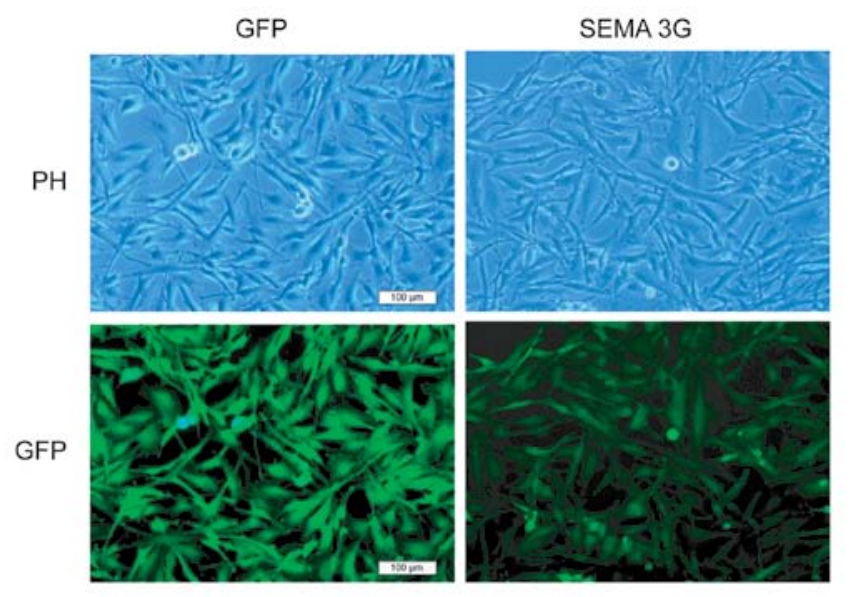

B

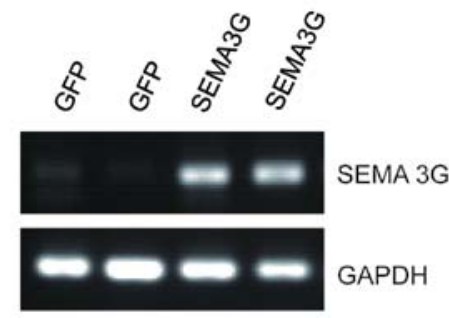

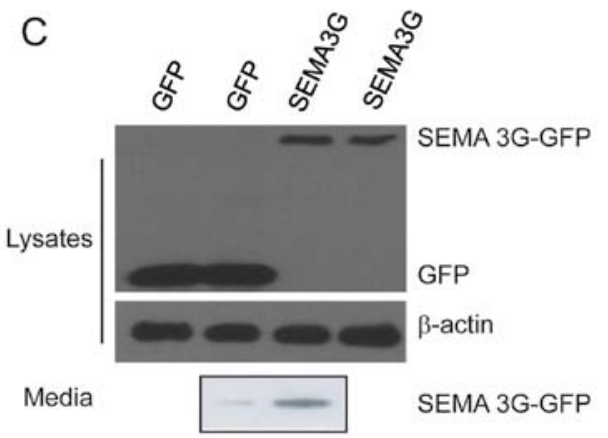

Figure 1. Stable expression of SEMA 3G in U251MG cells. (A) Morphological features of SEMA 3G overexpressing glioma cells. U251MG cells were stably infected with GFP or SEMA 3G-GFP as indicated. PH, phase contrast. Scale bar, $100 \mu \mathrm{m}$. (B) The mRNA level of SEMA 3G in GFP or SEMA 3G-GFP overexpressing glioma cells. After G418 selection for 2 months, total RNA of U251 cells transfected with GFP or SEMA 3G-GFP were extracted and analyzed by using RT-PCR. GAPDH served as a control. (C) The protein level of SEMA 3G in GFP or SEMA 3G-GFP overexpressing glioma cell lysates and culture media. Equal amount of protein from each cell line or equal amount of media were immunoblotted with antibody against GFP. $\beta$-actin was the loading control.

$1 \mathrm{mg} / \mathrm{ml}$ gelatin. After electrophoresis, the gels were washed several times in $2.5 \%$ Triton $\mathrm{X}-100$ for $1.5 \mathrm{~h}$ to remove SDS, then incubated in reaction buffer $(50 \mathrm{mmol} / \mathrm{l}$ Tris- $\mathrm{HCl} \mathrm{pH} 7.5$, $10 \mathrm{mmol} / \mathrm{l} \mathrm{CaCl}_{2}, 1 \mu \mathrm{mol} / 1 \mathrm{ZnCl}_{2}$ and $1 \%$ Triton X-100) for $18 \mathrm{~h}$ at $37^{\circ} \mathrm{C}$ to promote activity of proteinases. Gels were stained for $2 \mathrm{~h}$ with $0.25 \%$ coomassie blue and destained with $45 \%$ methanol and $10 \%$ acetic acid. Proteolytic activity was visualized as clear bands (zones of gelatin degradation, $\sim 65 \mathrm{kDa}$ corresponded to MMP2) against the blue background of stained gelatin (30).

Statistical analysis. Statistical analysis for protein and mRNA levels, cell migration and invasion was performed using a two-sided Student's t-test. In all analysis, quantitative data were obtained from at least three independent experiments and expressed as means \pm SEM. P-values $<0.05$ were considered statistically significant $\left({ }^{*} \mathrm{P}<0.05,{ }^{* *} \mathrm{P}<0.01\right)$. All statistical analyses were performed using Office Excel 2004 (Microsoft Corp.) or SPSS software (SPSS version 17.0).

\section{Results}

Stable expression of SEMA $3 G$ in U251MG cells. To exam the possible effect of SEMA $3 \mathrm{G}$ on glioma cell migration and invasion ability, we firstly generated the stable SEMA 3G expression U251MG cells by using SEMA 3G transfection combined with the classic G418 selection method. As shown in Fig. 1A, after G418 selection for 2 months, each cell stably expressing SEMA 3G-GFP (SEMA 3G group) or GFP (GFP group) showed GFP positive, although the fluorescence intensity of SEMA 3G group was weaker than that of GFP group. This phenomenon may be due to the fact that the nucleotide sequence of SEMA 3G-GFP $(>3 \mathrm{~kb})$ was far longer than that of GFP ( $700 \mathrm{bp})$, which led to difficult expression. Furthermore, the mRNA and protein levels of SEMA 3G was tested with RT-PCR and western blot assay, respectively. As Fig. $1 \mathrm{~B}$ and $\mathrm{C}$ show, compared with the GFP group, the mRNA and protein levels of SEMA 3G group increased dramatically. In addition, because SEMA3G is the ligand protein for NPR2, it means SEMA3G should be secreted out of cells. Therefore, we checked whether the stable SEMA3G overexpression cell line could secrete SEMA 3G-GFP. To test whether the SEMA 3G-GFP could be secreted by SEMA 3G overexpressing U251MG cells, the conditioned media were collected and tested by western blotting. The results showed that SEMA 3G-GFP could be secreted into culture media (Fig. 1C), indicating the stable SEMA 3G expression U251MG cell line was generated successfully.

SEMA $3 G$ decreases motility of U251MG cells. Next, we tested the effects of SEMA $3 \mathrm{G}$ on cell migration ability by wound healing assay. The repopulation of cells into a cell-free region 
A
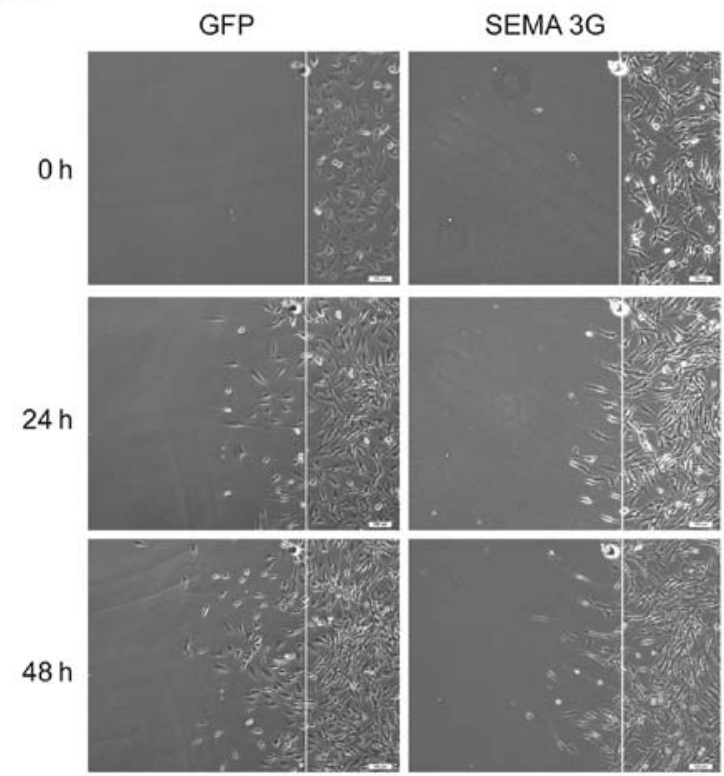

B
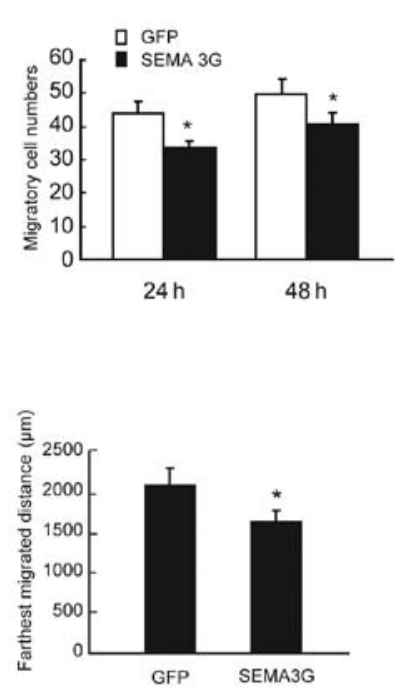

Figure 2. Effect of stable SEMA 3G overexpression on cell migration ability examined by wound healing assay. (A) Wound healing assays indicated that cells overexpressing SEMA 3G exhibited a strong reduction in migratory potential when compared with GFP-transfected cells. Representative digital images were taken at 0,24 and $48 \mathrm{~h}$. (B) Quantitative results of the stable cell lines overexpressing SEMA 3G-GFP or GFP using wound healing assays. Up, quantitative migratory cell numbers. Down, quantitative farthest migrated distance taken at $48 \mathrm{~h}$.

A

Media

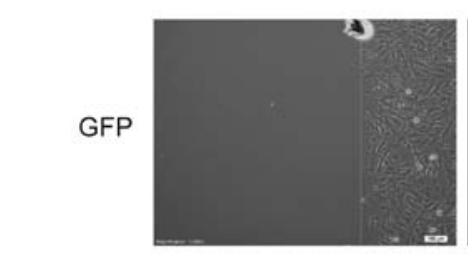

SEMA 3G

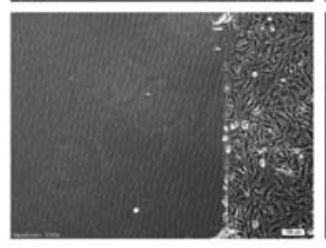

$24 \mathrm{~h}$
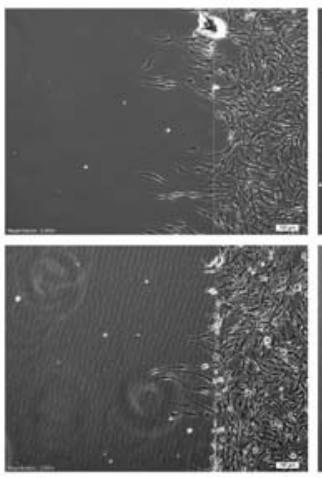

$48 \mathrm{~h}$
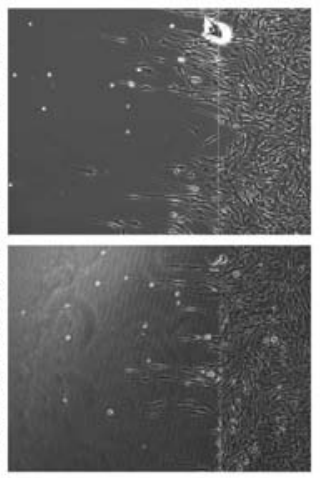

B
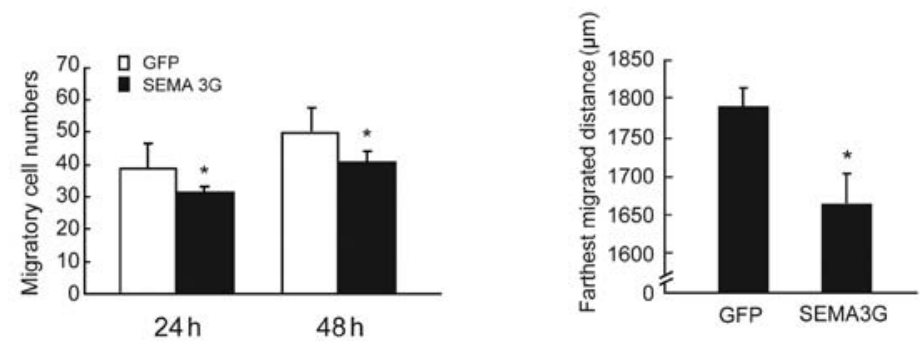

Figure 3. Effect of SEMA 3G conditioned media on cell migration ability examined by wound healing assay. (A) Wound healing assays indicated that cells treated with SEMA $3 \mathrm{G}$ conditioned media exhibited a strong reduction in migratory potential compared with GFP group media treatment. Representative digital images were taken at 0,24 and $48 \mathrm{~h}$. (B) Quantitative results of the SEMA $3 \mathrm{G}$ conditioned media or GFP group media treatment using wound healing assays. Left, quantitative migratory cell numbers. Right, quantitative farthest migrated distance taken at $48 \mathrm{~h}$.

(scar) was examined quantitatively. Compared with the GFP group, SEMA $3 \mathrm{G}$ group showed decreased migration ability both at 24 and $48 \mathrm{~h}$ after being scraped. Fig. 2A is a digital image of the scarred region at 0,24 and $48 \mathrm{~h}$ after being scraped from a typical experiment and the same experiment is quantified in Fig. 2B. The number of migratory cells in the scar for GFP group 
A

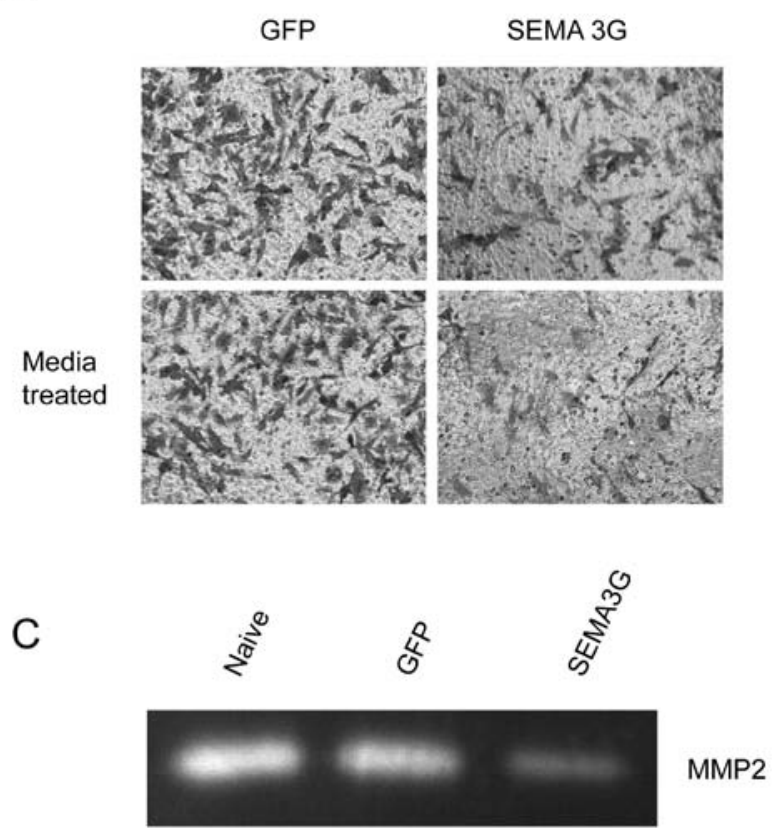

B
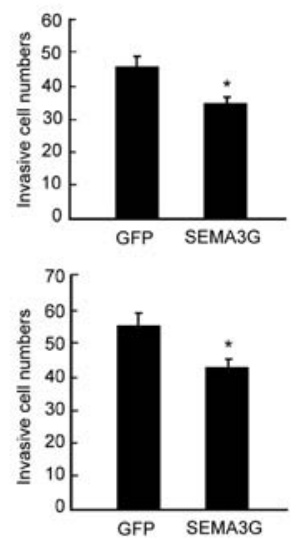

Figure 4. Effect of SEMA 3G on cell invasion ability examined by matrigel precoated transwell chambers (A) Stable SEMA 3G overexpressing cells or conditioned media treated glioma cells that invaded through matrigel-coated transwell inserts were stained with crystal violet. Stable SEMA 3G overexpressing or SEMA 3G conditioned media treatment inhibited the invasion ability of glioma cells. Upper panel, stable overexpression. Lower panel, conditioned media treatment. (B) Quantitative results of invasion assay. (C) Gelatin zymographic analysis of MMP-2 in conditioned media of GFP or SEMA 3G groups. The conditioned media of untransfected U251 cells (naive) was the negative control. Equal amount of samples were electrophoresed on SDS-PAGE gels containing gelatin as substrate to detect enzyme activity.

was $44.83 \pm 8.24(24 \mathrm{~h})$ and $54.41 \pm 8.31(48 \mathrm{~h})$, whereas the number of SEMA $3 \mathrm{G}$ group was $35.75 \pm 5.67$ ( $24 \mathrm{~h})$ and $46.91 \pm 7.05$ (48 h). Compared with the GFP group, the migratory cell numbers of SEMA 3G group decreased by $20 \%(24 \mathrm{~h}, \mathrm{P}<0.01)$ and $14 \%$ $(48 \mathrm{~h}, \mathrm{P}<0.05)$ respectively. The farthest distance migrated was quantified at the same time and the farthest distance of GFP group was $2030.91 \pm 257.12 \mu \mathrm{m}(48 \mathrm{~h})$, whereas the distance of SEMA 3G group was $1833.91 \pm 168.88 \mu \mathrm{m}(48 \mathrm{~h})(\mathrm{P}<0.05)$.

In addition, we treated the naïve U251MG cells with SEMA $3 \mathrm{G}$ conditioned media and repeated the above experiment. As Fig. 3 shows the cell migratory ability decreased significantly by SEMA $3 \mathrm{G}$ conditioned media treatment. The results were very similar to those of stable SEMA $3 \mathrm{G}$ overexpression. The migratory cell numbers in the scar for GFP group media treatment were $37.16 \pm 4.40(24 \mathrm{~h})$ and $48.66 \pm 5.05$ (48 h), whereas the number of SEMA $3 \mathrm{G}$ conditioned media treatment was $31.50 \pm 4.18(24 \mathrm{~h})$ and $41.75 \pm 4.93(48 \mathrm{~h})(\mathrm{P}<0.01)$. The farthest distance migrated was quantified at the same time and the distance of GFP group media treatment was 1786.91 $\pm 93.41 \mu \mathrm{m}$ (48 h), whereas the distance of SEMA $3 \mathrm{G}$ conditioned media treatment was $1669.41 \pm 70.44 \mu \mathrm{m}(48 \mathrm{~h})(\mathrm{P}<0.05)$.

SEMA $3 G$ decreases invasion of U251MG cells. As migration and invasion have close inter-communication and SEMA 3G decreases the migration of human glioma cells, we then examined the effect of SEMA $3 \mathrm{G}$ on invasion of U251MG cells using matrigel precoated transwell chambers. Fig. 4A showed representative digital image of the cells on the lower surface of the membrane from a typical experiment and the same experiment is quantified in Fig. 4B. The results showed that SEMA 3G decreased the invasion ability of human glioma cells significantly both in SEMA 3G group and SEMA 3G conditioned media treatment group. Compared with the GFP group, the invasive cell numbers of SEMA $3 \mathrm{G}$ group decreased by $23 \%(\mathrm{P}<0.05)$. The number of invasive cells for GFP group media treatment was $53.90 \pm 7.24(24 \mathrm{~h})$, whereas the number of SEMA $3 \mathrm{G}$ conditioned media treatment was 43.0 $\pm 5.52(24 \mathrm{~h})(\mathrm{P}<0.05)$.

Glioblastoma multiforme is a highly malignant brain tumor that is extremely refractory to therapy, partly because of aggressive tendency of the tumor cells to invade the surrounding tissues $(1,2)$. Numerous studies in vitro and in vivo have documented a direct correlation between high levels of matrix metalloproteinases (MMPs), a family of zinc-dependent endopeptidases, and increased invasive capacity of a large number of glioma cell lines (30). Thus, the MMPs activity is considered as an index of tumor invasion ability. Because the above data showed that SEMA 3G decreased the invasive ability of human glioma cells, we examined the MMPs activity by gelatin substrate gel zymography. As shown in Fig. $4 \mathrm{C}$, a clear band at $\sim 65 \mathrm{kDa}$ corresponding to MMP2 was visualized and the band intensity of SEMA 3G group was weaker than that of naïve and GFP overexpression cells, indicating SEMA $3 \mathrm{G}$ decreased the invasion ability of human glioma cells.

\section{Discussion}

In this study, we have shown that SEMA3G plays an important role in migratory and invasive behavior of glioma cells. We found that not only SEMA3G stably overexpressing U251MG cells showed decreased migration and invasion ability, but also SEMA3G conditioned media treatment inhibited naïve U251 cell migratory and invasive behavior. Our results thus suggest 
for the first time that SEMA3G possesses anti-migration and anti-invasion properties similar to those displayed by the previously identified tumor suppressor SEMA3s.

SEMA3s were firstly described as negative regulators of axonal guidance that repel axons and collapse growth cones $(31,32)$. Later, SEMA3s were found to play important roles in cell migration, development, tumorigenesis, and tumor angiogenesis. Several studies showed that Sema3A, Sema3B, SEMA3E, Sema3F, SEMA3G and their known receptors and coreceptors Plexin-A1, Plexin-A3, NRP1 and NRP2 decreased and have some relationship with disease progression $(11,33)$. SEMA3A can dramatically inhibit the proliferation and reduce both the migratory and invasive behavior of breast tumor cells $(9,10)$. SEMA3F is the most studied semaphorin and acts as a tumor suppressor gene by reducing angiogenesis and metastasis, probably through the inhibition of integrin mediated adhesion and VEGF expression (19,20,34-38). SEMA3B, like SEMA3F and SEMA3A, is also described as a tumor suppressor gene $(5,15)$.

As a recently identified semaphorin (39), scarce data have been published to our knowledge on the function of SEMA3G in tumors. Recently, it was reported that SEMA3G was the only significant prognostic marker in gliomas when a multivariate Cox analysis was performed (25). Because local invasion and migration of tumor cells are pivotal mechanisms in glioma progression, proteins involved in these processes are most likely important. To clarify the potential function of SEMA3 $\mathrm{G}$ in migratory and invasive behavior of glioma cells characterized by high migration potential, we generated SEMA3G stable expression U251MG cell line by using SEMA 3G transfection combined with the classic G418 selection method and analyzed its migratory and invasive behavior. We found that overexpressing SEMA3G inhibited the migration and invasion ability of U251MG cells either using the wound healing assay or with matrigel precoated transwell chambers. These results suggested that the effect of SEMA3G might be obtained through cell autonomous mechanism. Furthermore, we found that GFP tagged SEMA3G could be secreted into the culture media and SEMA3G conditioned media treatment also inhibited the migration and invasion ability of U251 parental cells, which indicated that SEMA 3G might exert its effect in a paracrine manner.

During tumor progression, cancer cells secrete various extracellular matrix degrading enzymes, including MMPs to facilitate their migration and invasion $(30,40)$. It is well established that MMPs are closely associated with tumor invasion and metastasis in a variety of human tumors. In particular, MMPs are highly expressed in gliomas compared with normal brain tissues, and their mRNA and protein levels further increased upon tumor progression. As is shown in our present study, overexpression of SEMA3G significantly inhibited MMP-2 activity, suggesting that this could be one mechanism by which SEMAs may attenuate tumor progression, including migration and cell invasion.

In conclusion, we reported for the first time that SEMA3G could reduce the migratory and invasive ability of U251MG cells and this effect might be obtained through cell autonomous or paracrine mechanism. Since U251MG cells have NRP2, the receptor for SEMA 3G and SEMA 3F, and SEMA3F blocked tumor formation by associating with loss of activated $\alpha v \beta 3$ integrin, impaired cell adhesion to extracellular matrix components $(36,41,42)$, it could be informative to determine the mechanism of SEMA3G in tumorigenesis and invasive progression.

\section{Acknowledgements}

This study was supported by the project of National Natural Science Foundation of China (no. 81072072), the grant from Xuzhou Medical College (no. 09KJZ18), and the grant from State Key Laboratory of Neuroscience, Shanghai Institutes for Biological Sciences, Chinese Academy of Sciences (no. SKLN2011A01).

\section{References}

1. Zalutsky MR: Current status of therapy of solid tumors: brain tumor therapy. J Nucl Med (Suppl 1): S151-S156, 2005.

2. Rao JS: Molecular mechanisms of glioma invasiveness: the role of proteases. Nat Rev Cancer 7: 489-501, 2003.

3. Luo Y, Raible D and Raper JA: Collapsin: a protein in brain that induces the collapse and paralysis of neuronal growth cones. Cell 75: 217-227, 1993.

4. Raper JA: Semaphorins and their receptors in vertebrates and invertebrates. Curr Opin Neurobiol 1: 88-94, 2000.

5. Tomizawa Y, Sekido Y, Kondo M, et al: Inhibition of lung cancer cell growth and induction of apoptosis after reexpression of 3 p21.3 candidate tumor suppressor gene SEMA3B. Proc Natl Acad Sci USA 24: 13954-13959, 2001.

6. Nasarre P, Constantin B, Rouhaud L, et al: Semaphorin SEMA3F and VEGF have opposing effects on cell attachment and spreading. Neoplasia 1: 83-92, 2003.

7. Nasarre P, Kusy S, Constantin B, et al: Semaphorin SEMA3F has a repulsing activity on breast cancer cells and inhibits E-cadherinmediated cell adhesion. Neoplasia 2: 180-189, 2005.

8. Kigel B, Varshavsky A, Kessler O and Neufeld G: Successful inhibition of tumor development by specific class-3 semaphorins is associated with expression of appropriate semaphorin receptors by tumor cells. PLoS One 9: e3287, 2008.

9. Bachelder RE, Lipscomb EA, Lin X, Wendt MA, Chadborn NH, Eickholt BJ and Mercurio AM: Competing autocrine pathways involving alternative neuropilin-1 ligands regulate chemotaxis of carcinoma cells. Cancer Res 17: 5230-5233, 2003.

10. Pan H, Wanami LS, Dissanayake TR and Bachelder RE: Autocrine semaphorin3A stimulates alpha2 beta1 integrin expression/function in breast tumor cells. Breast Cancer Res Treat 1: 197-205, 2009.

11. Rich JN, Hans C, Jones B, et al: Gene expression profiling and genetic markers in glioblastoma survival. Cancer Res 10: 4051-4058, 2005.

12. Rolny C, Capparuccia L, Casazza A, et al: The tumor suppressor semaphorin $3 \mathrm{~B}$ triggers a prometastatic program mediated by interleukin 8 and the tumor microenvironment. J Exp Med 5: 1155-1171, 2008.

13. Castro-Rivera E, Ran S, Thorpe $P$ and Minna JD: Semaphorin 3B (SEMA3B) induces apoptosis in lung and breast cancer, whereas VEGF165 antagonizes this effect. Proc Natl Acad Sci USA 31: 11432-11437, 2004

14. Castro-Rivera E, Ran S, Brekken RA and Minna JD: Semaphorin 3B inhibits the phosphatidylinositol 3-kinase/Akt pathway through neuropilin-1 in lung and breast cancer cells. Cancer Res 20: 8295-8303, 2008.

15. Tse C, Xiang RH, Bracht T and Naylor SL: Human Semaphorin 3B (SEMA3B) located at chromosome 3p21.3 suppresses tumor formation in an adenocarcinoma cell line. Cancer Res 2: 542-546, 2002.

16. Potiron VA, Roche J and Drabkin HA: Semaphorins and their receptors in lung cancer. Cancer Lett 1: 1-14, 2009.

17. Brambilla E, Constantin B, Drabkin H and Roche J: Semaphorin SEMA3F localization in malignant human lung and cell lines: A suggested role in cell adhesion and cell migration. Am J Pathol 3: 939-950, 2000.

18. Xiang R, Davalos AR, Hensel CH, Zhou XJ, Tse C and Naylor SL: Semaphorin 3F gene from human 3p21.3 suppresses tumor formation in nude mice. Cancer Res 9: 2637-2643, 2002.

19. Kusy S, Nasarre P, Chan D, et al: Selective suppression of in vivo tumorigenicity by semaphorin SEMA3F in lung cancer cells. Neoplasia 5: 457-465, 2005. 
20. Futamura M, Kamino H, Miyamoto Y, et al: Possible role of semaphorin $3 \mathrm{~F}$, a candidate tumor suppressor gene at 3p21.3, in p53-regulated tumor angiogenesis suppression. Cancer Res 4 : 1451-1460, 2007.

21. Bielenberg DR, Hida Y, Shimizu A, Kaipainen A, Kreuter M, Kim CC and Klagsbrun M: Semaphorin 3F, a chemorepulsant for endothelial cells, induces a poorly vascularized, encapsulated, nonmetastatic tumor phenotype. J Clin Invest 9: 1260-1271, 2004.

22. Wu F, Zhou Q, Yang J, et al: Endogenous axon guiding chemorepulsant semaphorin-3F inhibits the growth and metastasis of colorectal carcinoma. Clin Cancer Res 9: 2702-2711, 2011.

23. Gaur P, Bielenberg DR, Samuel S, et al: Role of class 3 semaphorins and their receptors in tumor growth and angiogenesis. Clin Cancer Res 22: 6763-6770, 2009.

24. Banu N, Teichman J, Dunlap-Brown M, Villegas G and Tufro A: Semaphorin $3 \mathrm{C}$ regulates endothelial cell function by increasing integrin activity. FASEB J 12: 2150-2152, 2006.

25. Karayan-Tapon L, Wager M, Guilhot J, et al: Semaphorin, neuropilin and VEGF expression in glial tumours: SEMA3G, a prognostic marker? Br J Cancer 7: 1153-1160, 2008.

26. Mariani L, Beaudry C, McDonough WS, et al: Glioma cell motility is associated with reduced transcription of proapoptotic and proliferation genes: a cDNA microarray analysis. J Neurooncol 2: 161-176, 2001.

27. Ritch PA, Carroll SL and Sontheimer H: Neuregulin-1 enhances motility and migration of human astrocytic glioma cells. J Biol Chem 23: 20971-20978, 2003

28. Lu X, Feng X, Man X, et al: Aberrant splicing of Hugl-1 is associated with hepatocellular carcinoma progression. Clin Cancer Res 10: 3287-3296, 2009.

29. Yim EK, Peng G, Dai H, et al: Rak functions as a tumor suppressor by regulating PTEN protein stability and function. Cancer Cell 4 304-314, 2009.

30. Koul D, Parthasarathy R, Shen R, et al: Suppression of matrix metalloproteinase-2 gene expression and invasion in human glioma cells by MMAC/PTEN. Oncogene 46: 6669-6678, 2001.
31. He Z and Tessier-Lavigne M: Neuropilin is a receptor for the axonal chemorepellent Semaphorin III. Cell 4: 739-751, 1997.

32. Kolodkin AL, Levengood DV, Rowe EG, Tai YT, Giger RJ and Ginty DD: Neuropilin is a semaphorin III receptor. Cell 4: 753-762, 1997.

33. Staton CA, Shaw LA, Valluru M, et al: Expression of class 3 semaphorins and their receptors in human breast neoplasia. Histopathology 2: 274-282, 2011.

34. Kessler O, Shraga-Heled N, Lange T, et al: Semaphorin-3F is an inhibitor of tumor angiogenesis. Cancer Res 3: 1008-1015, 2004.

35. Bielenberg DR, Pettaway CA, Takashima S and Klagsbrun M: Neuropilins in neoplasms: expression, regulation, and function. Exp Cell Res 5: 584-593, 2006.

36. Potiron VA, Sharma G, Nasarre P, et al: Semaphorin SEMA3F affects multiple signaling pathways in lung cancer cells. Cancer Res 18: 8708-8715, 2007.

37. Coma S, Amin DN, Shimizu A, Lasorella A, Iavarone A and Klagsbrun M: Id2 promotes tumor cell migration and invasion through transcriptional repression of semaphorin 3F. Cancer Res 9: 3823-3832, 2010.

38. Joseph D, Ho SM and Syed V: Hormonal regulation and distinct functions of semaphorin-3B and semaphorin-3F in ovarian cancer. Mol Cancer Ther 2: 499-509, 2010.

39. Taniguchi M, Masuda T, Fukaya M, et al: Identification and characterization of a novel member of murine semaphorin family. Genes Cells 8: 785-792, 2005.

40. Curran S and Murray GI: Matrix metalloproteinases in tumour invasion and metastasis. J Pathol 3: 300-308, 1999.

41. Zheng C, Zhou Q, Wu F, Peng Q, Tang A, Liang H and Zeng Y: Semaphorin $3 \mathrm{~F}$ down-regulates the expression of integrin alpha(v) beta3 and sensitizes multicellular tumor spheroids to chemotherapy via the neuropilin- 2 receptor in vitro. Chemotherapy 5 : 344-352, 2009.

42. Nguyen H, Ivanova VS, Kavandi L, Rodriguez GC, Maxwell GL and Syed V: Progesterone and 1,25-dihydroxyvitamin D3 inhibit endometrial cancer cell growth by upregulating semaphorin $3 \mathrm{~B}$ and semaphorin 3F. Mol Cancer Res 11: 1479-1492, 2011. 